Janusz Kaczmarek

Uniwersytet Łódzki

\title{
CO TO JEST HERMENEUTYKA TOPOLOGICZNA? OD HERMENEUTYKI LOGICZNEJ DO HERMENEUTYKI TOPOLOGICZNEJ, CZYLI O PEWNYCH METODACH FILOZOFII ANALITYCZNEJ ${ }^{1}$
}

\section{Wstęp}

Termin „hermeneutyka topologiczna” zawarty w tytule pracy nawiązuje celowo do wypracowanego przez Bogusława Wolniewicza pojęcia hermeneutyki logicznej. Przy tym hermeneutyka topologiczna zaproponowana w niniejszej pracy nie jest dokładnie tym samym, co hermeneutyka logiczna w ujęciu Wolniewicza. Tej sprawie, tj. hermeneutyce topologicznej, chcę w głównej mierze poświęcić niniejszą pracę - dedykowaną prof. Ryszardowi Kleszczowi, który w centrum zainteresowania swych dociekań stawia m.in. sprawy metod filozoficznych, w szczególności metod filozoficznych proponowanych przez filozofów analitycznych ${ }^{2}$.

\section{Hermeneutyka logiczna Wolniewicza}

W pracy Hermeneutyka logiczna Wolniewicz następująco charakteryzuje swoją metodę: "Za Diltheyem metodologię interpretacji tekstów filozoficznych będziemy nazywać filozoficzną hermeneutyką" (1998, s. 24). I dalej:

${ }^{1}$ Praca została wykonana przy wsparciu Narodowego Centrum Nauki, projekt" Atom. Substancja. System. Badania z zakresu ontologii topologicznej" (nr 2017/27//B/HS1/02830).

2 Por. rozprawę profesora Kleszcza (Kleszcz 1998) poświęconą racjonalności. Autor nie rozważa tu co prawda takich lub innych metod filozoficznych czy naukowych, ale podaje ogólne kryteria (metazasady), które winna spełniać każda racjonalna metoda. Owe metazasady sprowadzają się do czterech (rozdział 4, s. 104-127): ścisłość językowa, przestrzeganie zasad logiki, metazasada krytycyzmu (konieczność dokonywania krytyki koncepcji naukowych tak cudzych, jak i własnych oraz otwartość na krytykę własnych poglądów ze strony innych), rozwiązywalność problemu. 
Zgłębiać sens tekstu filozoficznego można dwojako. Pierwszy sposób polega na wmyślaniu się i wczuwaniu w intencje autora, co wspomagane jest zwykle wiedzą historyczną o autorze i jego epoce. [...] Drugi sposób polega na ujawnianiu struktury logicznej systemu filozoficznego zawartego w interpretowanym tekście. [...] Prawidła interpretacji są w obu przypadkach całkiem inne. W pierwszym nazywamy je hermeneutyką intuicyjną; w drugim - hermeneutyką logiczną (Wolniewicz, 1998, s. 25).

Wolniewicz opisuje swoją metodę w kilku etapach. Wychodzimy od pewnego systemu filozoficznego $S$ (np. tez atomizmu logicznego zawartych w Traktacie Ludwiga Wittgensteina (Wittgenstein 1997). Twierdzenia takiego systemu są zwykle podane $\mathrm{w}$ języku naturalnym, a naszym zadaniem jest przeprowadzenie logicznej interpretacji. Wolniewicz podkreśla, że tę interpretację można rozumieć dwojako: w sensie jej metody i w sensie jej wyniku. Stąd metodę interpretacji definiuje jako parę $M=(T, \Pi)$, gdzie $T$ jest pewną teorią formalna, zaksjomatyzowana, zwaną podstawą interpretacji, natomiast $\Pi$ jest zbiorem reguł przekładu, które przekształcają tezy systemu $S \mathrm{w}$ formuły języka sformalizowanego $J(T)$ teorii $T$. Dla przykładu teorią formalną może być zaproponowana przez Wolniewicza teoria sytuacji podana $\mathrm{w}$ języku teorii krat (Wolniewicz, 1985). Z kolei w zbiorze reguł przekładu będziemy mieć taką regułę, która mówi, że fakt atomowy należy rozumieć jako atom $w$ kracie, i będziemy mieć inną regułę, która nakazuje nam interpretować możliwy świat jako tak zwany element maksymalny w kracie (oczywiście tych reguł będzie więcej). $W$ istocie właściwymi regułami będą takie, które formułom $S$ przyporządkowują formuły $\mathrm{z} J(T)$. Jeśli więc w Traktacie mielibyśmy twierdzenie (wprost, w takiej formie, nie znajdziemy go): „dowolny stan rzeczy $A$ jest faktem pewnego możliwego świata", to w $J(T)$ znajdziemy formułę: dla dowolnego atomu $a \mathrm{w}$ kracie istnieje element maksymalny $w$ taki, że $a$ zachodzi w świecie $w$ (jest elementem świata $w$ ). Tę ostatnią formułę możemy wyrazić precyzyjnie $\mathrm{w}$ formalnym języku teorii krat.

Podajmy przykład kraty z Ontologii sytuacji Wolniewicza (1985), by wyjaśnić, na czym polegają przekład i interpretacja pewnych tez systemu filozoficznego.

Zbiór $\{a, b, c, d\}$ jest zbiorem atomów kraty, tj. atomowych stanów rzeczy. Atomowe i złożone stany rzeczy (np. $w_{1}$ ) Wolniewicz nazywa sytuacjami elementarnymi. Za Wolniewiczem ustalmy, że atomowe stany rzeczy oddajemy w języku naturalnym poprzez zdania - odpowiednio - ,jest chłodno", , jest mokro", , ,jest sucho", , ,jest ciepło". Pary: $\{a, d\}$ i $\{b$, c) są nazywane wymiarami (odpowiednio: temperatury i wilgotności), gdyż obiekty z jednego wymiaru wykluczają się. Wolniewicz zakłada ponadto, że liczba wymiarów jest skończona, ale liczba atomów w danym wymiarze może być dowolna - nawet nieskończona. Każda krata zawiera 


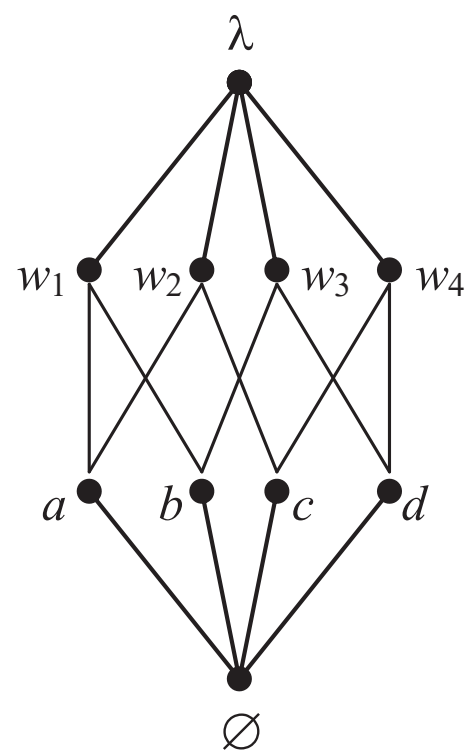

Rysunek 1. Krata o sygnaturze $(2,2)$ z dwoma wymiarami: $D_{1}=\{a, d\}$ i $D_{2}=\{b, c\}$.

co najmniej dwa elementy: sytuację niemożliwą $\lambda$ oraz sytuację pustą $\varnothing$ (zakładamy przy tym: $\varnothing \neq \lambda$ ). Wolniewicz określa dodatkowo, że zbiór $E S^{\prime}=S E-\{\lambda\}$ to $t z w$. zbiór możliwych sytuacji elementarnych, natomiast zbiór $C E S=E S-\{\varnothing, \lambda\}$ jest zbiorem sytuacji przygodnych (przypadkowych). Z kolei zbiór możliwych światów $\left\{w_{1}, w_{2}, w_{3}, w_{4}\right\}$ nazywa przestrzenią logiczną. Oczywiście spełniony jest warunek:

dla dowolnej sytuacji $x$ : $\varnothing \leq x \leq \lambda$.

Należy podkreślić, że zwykle zbiór reguł przekładu wyznacza jedynie funkcję częściową określoną na $S$ w zbiór formuł $J(T)$, co oznacza, że nie wszystkie formuły systemu filozoficznego $S$ możemy przełożyć na język formalny. Powiemy wówczas, że formuły takie „wymykają się" danej metodzie interpretacji, leżą poza zasięgiem takiej metody interpretacji.

Mamy też drugą stronę interpretacji: interpretację w sensie jej wyniku. Tę pojmuje Wolniewicz jako:

przekład części tez interpretowanego systemu na język jakiejś teorii zaksjomatyzowanej, dokonany według ustalonych reguł, a następnie wydzielenie wśród tych tez pewnego zbioru tez pierwotnych jako założeń owego systemu (1998, s. 27). 
Formalnie interpretacją logiczną w sensie jej wyniku jest para $\left(A, A^{0}\right)$ taka i tylko taka, że istnieje metoda interpretacji $(T, \Pi)$ i spełnione są warunki:

(a) $A \subset S, A \neq \varnothing, A^{0} \subset A$;

(b) П: $A \rightarrow J(T)$;

(c) $\Pi(A) \subset \mathrm{Cn}_{\mathrm{T}}\left(\Pi\left(A^{0}\right)\right)$ (tj. zbiór wszystkich konsekwencji formuł będących przekładem zdań systemu filozoficznego $A^{0}$ jest szerszy niż zbiór wszystkich formuł będących przekładem zdań $A$ ).

Dopisek w warunku (c) oznacza, że „na gruncie teorii $T$ i przy przekładzie $\Pi$ każda teza zbioru $A$ jest konsekwencją logiczną zbioru $A^{0}$. Zbiór $A^{0}$ może więc być rozumiany jako zbiór aksjomatów systemu $S$. Wyjaśnijmy ponadto, że interpretacja logiczna w sensie wyniku będzie polegała $\mathrm{u}$ Wolniewicza na przekładzie pewnych tez Traktatu Wittgensteina na język teorii krat i wskazaniu zależności między poszczególnymi tezami Traktatu. W szczególności można $\mathrm{w}$ ten sposób „wyłowić" tezy pierwotne jako założenia systemu. Dla przykładu Wolniewicz pokazuje, w jaki sposób przełożyć na język teorii krat tezy Wittgensteina:

\section{2. Świat rozpada się na fakty.}

1.21. Jedno może być faktem lub nie, a wszystko inne pozostawać, jak jest.

Odpowiednikiem tezy 1.2 Wittgensteina jest teza teorii krat:

1.2'. Dla dowolnego możliwego świata $w$ istnieją sytuacje atomowe $a_{1}, \ldots, a_{n}$ takie, że: $w=\sup \left(a_{1}, \ldots, a_{n}\right)$ (innymi słowy: dowolny świat jest splotem, kresem górnym, atomów z poszczególnych wymiarów).

Zauważmy, że w przypadku kraty na rysunku 1 świat $w_{1}$ jest kresem górnym atomów $a \mathrm{i} b$, natomiast świat $w_{2}$ kresem górnym atomów $a \mathrm{i} c$.

Z kolei odpowiednikiem tezy 1.21 Wittgensteina jest teza teorii krat:

1.21 '. Dla dowolnych atomowych stanów rzeczy $a$ i $b$ istnieje $w$ takie, że $a \in w$ i $b \in w$ oraz istnieje takie $w$, że $a \notin w$ i $b \in w$.

W przykładzie Wolniewicza z rysunku 1 zauważamy, że sytuacja (atomowa) $b$ zachodzi w świecie $w_{1}$, natomiast nie zachodzi w świecie $w_{2}$. 
W ten sposób możemy „wyłowić” tezy pierwsze. Wolniewicz pokazuje m.in., że teza 1.2 pociąga za sobą tezę 1.21 . Ta pierwsza zatem jest właściwą zasadą atomizmu logicznego, druga natomiast - jej konsekwencją ${ }^{3}$.

\section{Metoda parafraz Ajdukiewicza}

Kazimierz Ajdukiewicz opracował metodę parafraz - jedną z bardziej interesujących metod filozoficznych, które pojawiły się w filozofii analitycznej - w latach 30. ubiegłego wieku. Omawiał i wykorzystywał jac do rozwiązywania pewnych problemów filozoficznych m.in. w pracach z lat 1934 i $1937^{4}$. Przedstawmy szkicowo tę metodę w odniesieniu do zagadnienia idealizmu transcendentalnego zaprezentowaną przez Ajdukiewicza w pracy Język i poznanie (1985b) ${ }^{5}$.

Idealizm transcendentalny to kierunek filozoficzny zaproponowany przez Kanta. Jedną z tez idealizmu (TIT) jest teza następująca:

(TIT) Świat jest korelatem podmiotu poznającego.

Teza ta nie jest w pełni czytelna, bo moglibyśmy zapytać, jak pojmuje się tu świat (np. czy jest to świat fenomenalny, czy noumenalny albo czy chodzi o świat badany przez fizykę - a więc świat materialny, czy przez humanistykę - a więc świat przedmiotów, w którym interesują nas zarówno pytania o przedmioty materialne, jak i pytania o rośliny, zwierzęta, człowieka, kulturę czy naukę). Zrozumienie tezy wymaga też wyjaśnienia, czym jest podmiot poznający. Ajdukiewicz zdawał sobie sprawę z tych trudności (z wagi tych pytań) i rozumował następująco:

a) Główną tezą idealizmu transcendentalnego jest teza przedstawiona w punkcie (TIT).

b) Opuszczając pytania o rozumienie świata, Ajdukiewicz zauważa, że podmiot poznający był rozumiany różnie przez zwolenników idealizmu transcendentalnego:

${ }^{3}$ Oczywiście pojawia się tu problem następujący. W proponowanej przez Wolniewicza teorii sytuacji ujętej $w$ języku teorii krat mamy przyjęte aksjomaty (jest ich minimum sześć); czy odpowiedniki tych aksjomatów dają się wyczytać z tez Traktatu? Raczej nie. Wolniewicz nie porusza tego wątku, ale wydaje się, że mówiąc o operacji konsekwencji na formułach przełożonych na język formalny, należy dorzucić aksjomaty samej teorii formalnej.

${ }^{4}$ Por. (Ajdukiewicz, 1985a; 1985b).

${ }^{5}$ Por. (Kaczmarek, 2008a, s. 228-229). 
1) Sam Kant miał na myśli podmiot ludzki w sensie idealnym, gatunkowym (z jego apriorycznymi formami zmysłowości, kategoriami intelektu i ideami rozumu).

2) Później kantyści utożsamili podmiot z mnogością idealnych (logicznych) pojęć i sądów,

3) a u Rickerta podmiot poznający to system (układ) norm transcendentalnych ${ }^{6}$.

c) Ajdukiewicz przekonuje, że pewne fragmenty języka naturalnego, a w szczególności język nauk przyrodniczych (a to jest właściwy język podmiotu poznającego), ma charakter sytemu dedukcyjnego; język ten jest na tyle bogaty, że zawiera w sobie arytmetykę.

d) Skoro tak, to należy wziąć pod uwagę, że języki bogate są niezupełne (wynika to $\mathrm{z}$ podstawowych twierdzeń metalogiki); oznacza to, że w tych językach są pewne prawdy, które nie są tezami lub inaczej mówiąc: nie są zdaniami, które „ocenić” może system dedukcyjny (są to prawdy, które nie dają się udowodnić).

e) To zaś ma oznaczać według Ajdukiewicza, że język nauk przyrodniczych nie może odzwierciedlić wszystkich prawd, które zachodzą w świecie.

f) Jeśli tak, to świat nie jest korelatem podmiotu poznającego; możemy zaryzykować twierdzenie, że tylko fragment świata jest korelatem podmiotu, ale nie cały.

W ten sposób, odwołując się do wyników metalogiki, Ajdukiewicz zakwestionował zasadność tezy idealizmu transcendentalnego. Siła tej metody, metody parafraz, nie polega na tym, że zakwestionowano tezę filozoficzną przy użyciu metod formalnych. Jej waga leży w tym, że precyzyjnie pokazano sposób analizy trudnych tez filozoficznych. Tezie: "Świat jest korelatem podmiotu poznającego (norm transcendentalnych)", odpowiada logiczna parafraza: „To, co daje się ująć jako prawda świata, jest tezą nauk przyrodniczych opartą na normach transcendentalnych". Tymczasem owa logiczna parafraza okazuje się prawda, której w języku nauk przyrodniczych udowodnić nie potrafimy (dokładnie: nie każdą prawdę naszego świata potrafimy udowodnić).

Metoda Ajdukiewicza jest pewnym ogólnym schematem pokazującym, w jaki sposób możemy wykorzystać teorie formalne do analizy problemów filozoficznych redagowanych najczęściej w języku naturalnym. Sądzę, że metoda Wolniewicza jest pewną odmianą metody parafraz

${ }^{6}$ Jest problematyczne, jak rozumieć owe normy transcendentalne. Ajdukiewicz nie potrafił tego jednoznacznie sprecyzować. W niniejszym artykule zakładam, że Rickertowi chodziło o takie podstawowe normy bądź zasady jak w myśli Kartezjusza, gdy przyjmuje się za normę, iż dwa boki w trójkącie są większe od trzeciego. Są to więc zdania (sądy) aprioryczne. 
Ajdukiewicza. Podobnie metoda hermeneutyki topologicznej, o której piszę poniżej, może być rozumiana jako odmiana ogólnego schematu Ajdukiewiczowskiej propozycji.

\section{Hermeneutyka topologiczna}

Hermeneutyka (interpretacja), którą tu nazywam topologiczna, wpisuje się w model metody zaproponowany przez Ajdukiewicza. Jest metodą analizy pojęć i twierdzeń pewnego systemu filozoficznego $S$ przy użyciu pojęć i twierdzeń topologii ogólnej. Tu również chodzi o ujawnienie struktury logicznej systemu filozoficznego, choć proponuję rozszerzyć to określenie i mówić o ujawnianiu struktury formalnej (logicznej, topologicznej, algebraicznej) systemu filozoficznego. Często też zamiast mówienia o przekładzie tez systemu filozoficznego $S$ na język pewnej teorii formalnej mówię o modelowaniu pojęć i twierdzeń (głównie ontologii) w języku topologii ogólnej.

\subsection{Czterokategorialna ontologia Lowe'a}

Rozważmy przykład ontologii zaproponowanej przez E.J. Lowe'a (2006). Brytyjski filozof, wyraźnie czerpiąc z nauki Platona o ideach, proponuje diagram charakteryzujący podstawowe kategorie ontologiczne. Należą do nich: rodzaje, atrybuty, indywidua oraz tropy (własności indywidualne). Pomiędzy wskazanymi kategoriami zachodzą też odpowiednie relacje: "jest charakteryzowany przez" (is characterized by), ",jest konkretyzowany przez" (is instantiated by) oraz "jest egzemplifikowany przez" (is exemplified by) ${ }^{7}$.

Przykładami rodzajów są człowiek w ogóle, pomidor w ogóle, przykładami atrybutów - rozumność, okrągłość. Z kolei indywidua to dla Lowe'a konkretne obiekty, jak Sokrates czy ten oto pomidor na talerzu, natomiast przykładami tropów są konkretne własności indywiduów, jak np. rozumność Sokratesa bądź czerwień tego oto pomidora ${ }^{8}$. Możemy też powiedzieć, że Sokrates „konkretyzuje” rodzaj „człowiek” i podobnie okrągłość jest konkretyzowana przez okragły kształt tego oto pomidora. Następnie rodzaj „człowiek” jest charakteryzowany przez rozumność, tak jak Sokrates przez sokratejską rozumność. Natomiast abstrakcyjne przedmioty, takie jak atrybuty, są egzemplifikowane przez konkretne obiekty - rozumność przez Sokratesa, a czerwoność przez ten oto pomidor.

7 Por. (Lowe 2006, s. 18).

${ }^{8}$ Precyzyjne określenia tych i innych kategorii podałem m.in. w (Kaczmarek 2008a). 


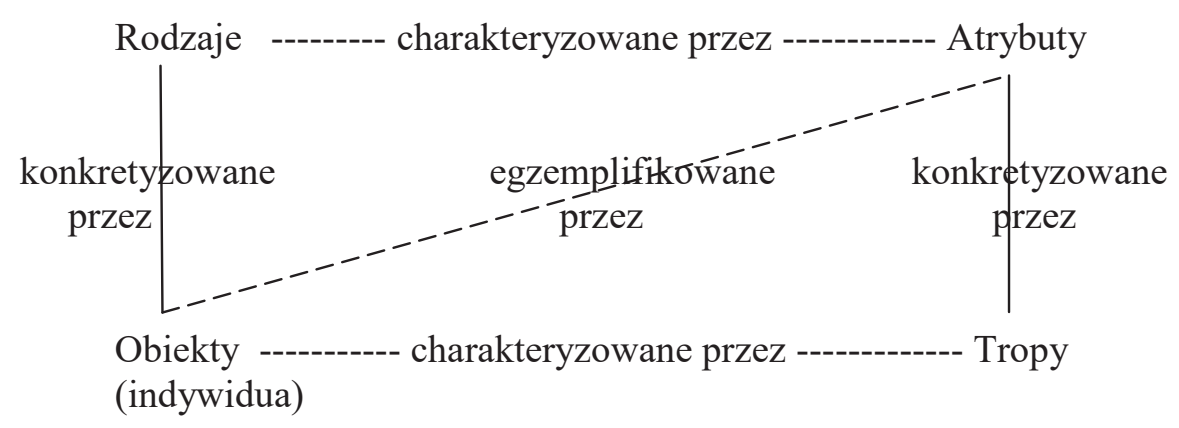

Rysunek 2. Diagram Lowe'a.

W ramach ontologii topologicznej (czasem nazywam ją również topoontologią) kategorie i relacje tu analizowane mogą być modelowane przy użyciu języka topologii ogólnej. Powyższy diagram uzyska wówczas następującą postać:

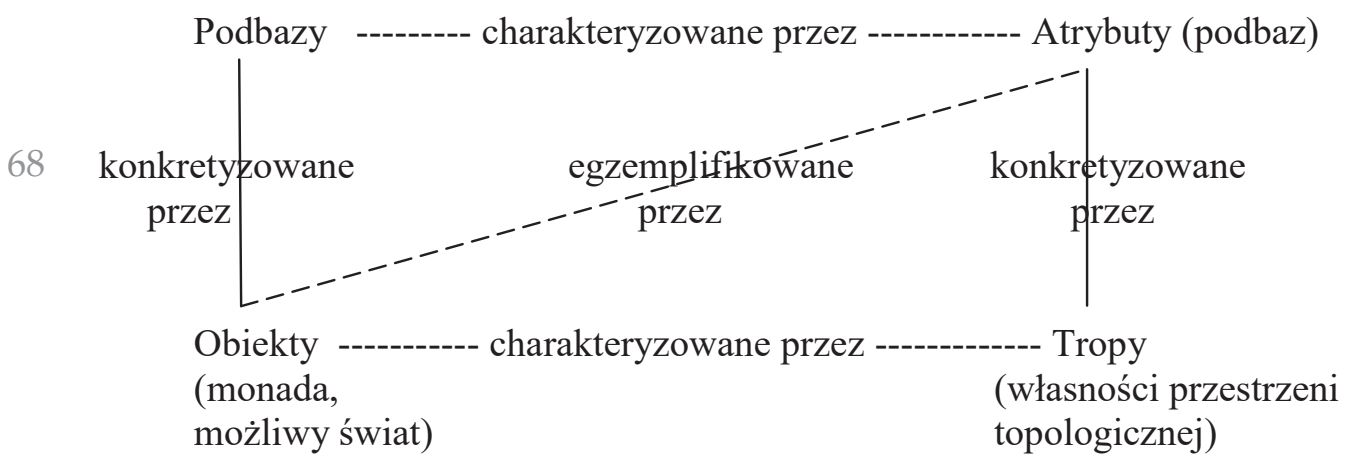

Rysunek 3. Diagram ontologii topologicznej.

Wyjaśnijmy zatem, co otrzymaliśmy. W topoontologii udało się pokazać, że odpowiednia krata złożona z przestrzeni topologicznych jest uogólnieniem kraty sytuacji elementarnych zaproponowanej przez Wolniewicza9 ${ }^{9}$. Wówczas elementom kraty Wolniewicza, które są pod pewnym możliwym światem $w_{i}$ odpowiada jedna przestrzeń topologiczna ${ }^{10}$. Przykładowo w kracie na rysunku 1 zbiór $\left\{\varnothing,\{a\},\{b\},\left\{w_{2}\right\}\right\}$, gdzie $\left\{w_{2}\right\}$ rozumiemy jako $\{a, b\}$ jest przykładem prostej przestrzeni dyskretnej

${ }^{9}$ Szczegóły tej konstrukcji zawarłem w artykule (Kaczmarek 2019).

${ }^{10}$ Nie przedstawiam w niniejszym artykule podstawowych pojęć topologii ogólnej, gdyż wydłużyłoby to niepotrzebnie prowadzoną tu analizę. Odpowiednie pojęcia wprowadzam intuicyjnie, ilustrując je przykładami. Czytelnik zainteresowany podstawowymi pojęciami topologii może znaleźć je m.in. w (Kaczmarek 2019; Kuratowski 1977). 
na zbiorze $\{a, b\}$. Ogólnie każdą kratę Wolniewicza łatwo przekształcić w kratę złożoną z przestrzeni topologicznych, które określone są na zbiorze atomów jednego z możliwych światów. Podobnie substancję możemy rozumieć jako układ odpowiednich przestrzeni topologicznych, a monadę jako układ definiowany na podstawie definicji przestrzeni topologicznej ${ }^{11}$. Na rysunku 3 pojawił się termin „podbaza”. Wyjaśnijmy, przestrzenią topologiczną jest para $(X, T(X))$, gdzie $X$ jest dowolnym zbiorem, a $T(X)$ rodziną podzbiorów zbioru $X$ taka, która zawiera $\varnothing$ i $X$ oraz jest zamknięta na skończone iloczyny i dowolne sumy. Natomiast podbazą przestrzeni $(X, T(X))$ jest każda taka rodzina zbiorów $P B$, która ma własność: dowolny zbiór z $T(X)$ może być przedstawiony jako suma skończonych iloczynów ze zbioru $P B$. By podać banalny przykład, wskażmy, że podbazą dla przestrzeni topologicznej $(\{a, b\},\{\varnothing,\{a\},\{b\},\{a, b\}\})$ jest rodzina $P B=\{\{a\},\{b\}\}$. W topologii ogólnej faktem jest, że dla danej przestrzeni topologicznej możemy zwykle znaleźć wiele podbaz. Co to oznacza? Wiemy już, że konkretne przedmioty, indywidua, konkretyzują rodzaje. W naszym przypadku w miejsce rodzajów wstawiliśmy podbazy, natomiast w miejsce indywiduów - przestrzenie topologiczne, które są formalnym odpowiednikiem monad albo możliwych światów. Powiemy więc, że dany możliwy świat konkretyzuje rodzaj „możliwy świat”. Przy tym dany możliwy świat jest - w zaproponowanej tu ontologii topologicznej - przestrzenią topologiczna, a rodzaj jej podbazą. Relacja konkretyzowania może więc być opisana precyzyjnie (w języku topologii ogólnej) jako relacja między przestrzenią topologiczną a jej podbazą. Podobnie moglibyśmy opisać pozostałe relacje wskazane przez Lowe'a w diagramie.

Zauważmy, że otrzymujemy również nieoczekiwane twierdzenie formalne: dany obiekt może konkretyzować różne rodzaje (bo, jak zauważyliśmy, przestrzeń topologiczna ma wiele różnych podbaz). W języku ontologii Platona oznaczałoby to, że jedna substancja pierwsza „podpada” pod różne rodzaje, a więc np. Sokrates konkretyzuje „różne natury (ludzkie?)". Brzmi to paradoksalnie, ale jednocześnie inspiruje do rewizji nauki Platona (i Lowe'a).

\subsection{Twierdzenia formalne. Twierdzenia interpretacyjne}

W pracy Indywidua. Idee. Pojęcia. Badania z zakresu ontologii sformalizowanej (Kaczmarek 2008a) wprowadziłem rozróżnienie twierdzeń ontologii formalnej. Pewne z nich są zapisywane w języku logiki, algebry czy topologii i nazywam je twierdzeniami formalnymi. Do nich należą twierdzenia

11 Piszę o tym m.in. w (Kaczmarek 2016). 
teorii sytuacji w ujęciu Wolniewicza czy moje propozycje w ujęciu topologii ogólnej. Oprócz tego w ontologii formalnej występują tzw. twierdzenia interpretacyjne. Należą do nich takie, które nie dają się sformułować w języku formalnym, ale które można sformułować w języku naturalnym na podstawie interpretacji twierdzeń formalnych. Ponieważ mamy mało materiału formalnego, więc zilustrujmy twierdzenia interpretacyjne następującymi przykładami.

Ajdukiewicz założył, że język, którym opisujemy świat, jest bogatym systemem dedukcyjnym zawierającym arytmetykę. Takie systemy nie są pełne i stąd pewne prawdy nie mogą być w tym języku (w teorii) udowodnione. Gdyby jednak Ajdukiewicz przyjął, że świat da się opisać przy użyciu pewnej teorii spełniającej twierdzenie o pełności (np. logika pierwszego rzędu), wówczas musiałby uznać tezę idealizmu transcendentalnego. Twierdzenie o niezupełności arytmetyki nie należy do systemu samej arytmetyki, twierdzenie o pełności logiki pierwszego rzędu nie jest twierdzeniem samej logiki i podobnie twierdzenie o tym, jakie założenia należy przyjąć, a jakie odrzucić, by otrzymać system pełny, jest twierdzeniem interpretacyjnym, które wyrażamy w języku naturalnym lub w metalogice.

Powyżej otrzymaliśmy zaskakującą tezę ontologii topologicznej: in70 dywiduum „podpada” pod różne rodzaje. Okazuje się jednak, że moglibyśmy rozumieć rodzaj jako klasę wszystkich podbaz generujących daną topologię, a relację konkretyzacji jako relację między indywiduum a elementem tej klasy. Wówczas każde indywiduum związane byłoby z dokładnie jednym rodzajem. Ponownie powiemy: twierdzenia o tym, jak zmodyfikować pojęcie rodzaju, aby otrzymać różne rodzaje dla jednego indywiduum bądź jeden rodzaj dla danego indywiduum, są twierdzeniami interpretacyjnymi.

Sądzę, że wprowadzenie pojęć: twierdzenia formalne, twierdzenia interpretacyjne, jest interesującą korektą propozycji Ajdukiewicza i Wolniewicza. W przypadku ich metod również można mówić o twierdzeniach interpretacyjnych. Przykładowo widzimy różnicę, której nie opisze się formułą teorii krat, między ogólną teorią sytuacji (spełnia ona sześć pierwszych aksjomatów podanych przez Wolniewicza), a teorią sytuacji, która w zamierzeniu Wolniewicza jest adekwatna dla teorii Traktatu (10 aksjomatów oraz założenie o dwuelementowości każdego wymiaru). Z kolei gdy uogólnimy teorię Wolniewicza na kraty złożone z przestrzeni dyskretnych oraz rozważymy dowolną (także nieskończoną) liczbę wymiarów, otrzymujemy nowe twierdzenia, których nie da się uzyskać w samej teorii krat sytuacji elementarnych ${ }^{12}$.

\footnotetext{
${ }^{12}$ Formalne twierdzenia na ten temat Czytelnik może znaleźć w (Kaczmarek 2019).
} 


\section{Bibliografia}

Ajdukiewicz K. (1985a), O stosowalności czystej logiki do zagadnień filozoficznych, [w:] idem, Jezyk i poznanie, t. 1, PWN, Warszawa.

Ajdukiewicz K. (1985b), Problemat transcendentalnego idealizmu w sformułowaniu semantycznym, [w:] idem, Jezzyk i poznanie, t. 1, PWN, Warszawa, s. 264-277.

Kaczmarek J. (2008a), Indywidua. Idee. Pojęcia. Badania z zakresu ontologii sformalizowanej, Wydawnictwo Uniwersytetu Łódzkiego, Łódź.

Kaczmarek J. (2008b), What is a Formalized Ontology Today? An Example of IIC, "Bulletin of the Section of Logic" 37, 3-4, s. 233-244.

Kaczmarek J. (2016), Atom ontologiczny: atom substancji, „Przegląd Filozoficzny. Nowa Seria" 25, 4(100), s. 131-145.

Kaczmarek J. (2019), Ontology in Tractatus Logico-Philosophicus: A Topological Approach, [w:] G. Mras, P. Weigertner, B. Ritter (red.), Philosophy of Logic and Mathematics, s. 245262.

Kleszcz R. (1998), O racjonalności. Studium epistemologiczno-metodologiczne, Wydawnictwo Uniwersytetu Łódzkiego, Łódź.

Kuratowski K. (1977), Wstęp do teorii mnogości i topologii (wraz z dodatkiem R. Engelkinga: Elementy topologii algebraicznej). (Introduction to Set Theory and Topology with a supplement by R. Engelking: Elements of algebraic topology), PWN, Warszawa.

Lowe E.J. (2006), The Four-Category Ontology: A Metaphysical Foundation for Natural Science, Oxford University Press, Oxford.

Wittgenstein L. (1997), Tractatus logico-philosophicus, tłum. i wstęp B. Wolniewicz, BKF, Wydawnictwo Naukowe PWN, Warszawa.

Wolniewicz B. [1983] (1998), Hermeneutyka logiczna, „Studia Filozoficzne”, 7, s. 27-40.

Wolniewicz B., (1985), Ontologia sytuacji, PWN, Warszawa.

Streszczenie: Co to jest hermeneutyka topologiczna? Od hermeneutyki logicznej do hermeneutyki topologicznej, czyli o pewnych metodach filozofii analitycznej

W artykule zaproponowałem nową metodę analityczna, którą nazwałem topologiczną hermeneutyką. $W$ rozdziałach 2 i 3 przypomniałem znane metody filozofii analitycznej, a mianowicie: metodę hermeneutyki logicznej zaproponowaną przez Wolniewicza w latach 80. XX wieku oraz wcześniejszą metodę, tj. metodę parafraz, podaną przez Ajdukiewicza już w latach 30 . W kolejnym punkcie (w rozdziale 4 ) zaproponowałem i wyjaśniłem, na czym polega interpretacja i modelowanie w ramach ontologii topologicznej. Tu wskazałem pewne rozwiązania na przykładzie czterokategorialnej ontologii Lowe'a oraz wyjaśniłem sens twierdzeń formalnych i interpretacyjnych, które - według mnie - są podstawą metodologii ontologii formalnej w tym topologicznej.

Słowa kluczowe: hermeneutyka logiczna, hermeneutyka topologiczna, metoda parafraz, metody filozofii analitycznej, ontologia topologiczna, twierdzenia formalne, twierdzenia interpretacyjne 
Summary: What is a Topological Hermeneutics? From Logical Hermeneutics to Topological Hermeneutics, that is, about Certain Methods of Analytical Philosophy

In the paper I proposed a new analytical method, which I called topological hermeneutics. In Chapters 2 and 3 I recalled the well-known methods of analytical philosophy, namely: the method of logical hermeneutics proposed by Wolniewicz in the 1980s and the earlier method, i.e. the paraphrase method given by Ajdukiewicz in the 1930s. In the next point (in Chapter 4) I proposed and explained what the interpretation and modelling within the topological ontology is. Here I pointed out some solutions on the example of Lowe's four-category ontology and explained the meaning of formal and interpretative theorems, which - in my opinion - are the basis of the formal ontology methodology in this topological one.

Keywords: logical hermeneutics, topological hermeneutics, paraphrase method, methods of analytical philosophy, topological ontology, formal theorems, interpretative theorems 